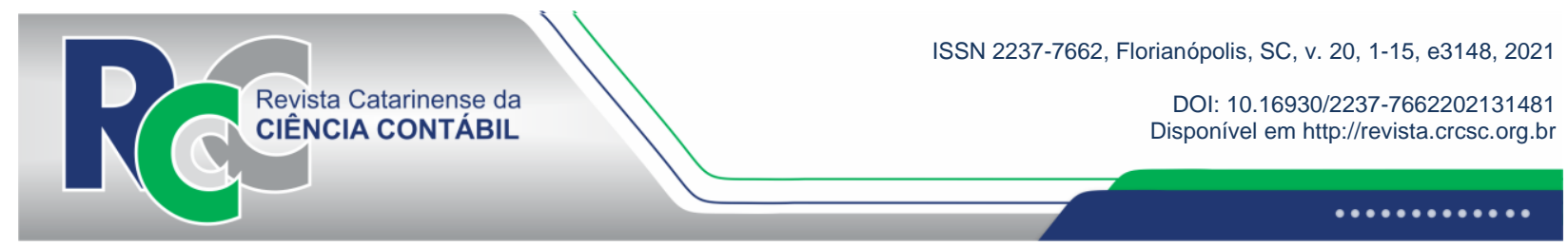

\title{
COST STICKINESS NOS GOVERNOS LOCAIS DE SANTA CATARINA
}

\section{COST STICKINESS IN THE LOCAL GOVERNMENTS OF SANTA CATARINA}

\author{
MARIANA CAMPAGNONI \\ Universidade Federal Rural do Rio de Janeiro \\ Endereço: BR 465, Km 07 | Zona Rural | 23890-000 | \\ Seropédica/RJ | Brasil. \\ (1) https://orcid.org/0000-0001-6069-2385 \\ marianacampagnoni@ufrrj.br
}

\author{
VALKYRIE VIEIRA FABRE \\ Universidade do Estado de Santa Catarina \\ Endereço: Rua Dr. Getúlio Vargas, $2822 \mid$ Bela Vista | \\ 89140-000 |Ibirama/SC | Brasil. \\ (1) https://orcid.org/0000-0002-4664-1415 \\ valkyrie.fabre@udesc.br
}

\author{
ALTAIR BORGERT \\ Universidade Federal de Santa Catarina \\ Endereço: Campus Universitário, CSE/CCN | Trindade | \\ 88040-900 | Florianópolis/SC | Brasil. \\ (1) https://orcid.org/0000-0002-0116-8089 \\ altair@borgert.com.br
}

\author{
SULIANI ROVER \\ Universidade Federal de Santa Catarina \\ Endereço: Campus Universitário, CSE/CCN | Trindade | \\ 88040-900 | Florianópolis/SC | Brasil. \\ (1) https://orcid.org/0000-0001-8612-2938 \\ suliani.rover@ufsc.br
}

\section{RESUMO}

O comportamento assimétrico dos custos teve nova abordagem, a partir de 2003, com o surgimento da Teoria dos Cost Stickiness (TCS) e, por ser algo recente, ainda restam dúvidas sobre sua aplicação no setor público. Neste sentido, o presente estudo tem como objetivo analisar o comportamento dos custos nos governos locais de Santa Catarina, na perspectiva dos cost stickiness. Trata-se de uma pesquisa empírica, quantitativa e documental, que utilizou como população os 295 municípios catarinenses, durante o lapso temporal de 20 anos, cuja transposição do modelo de análise foi adaptada para o setor público. Os custos foram agrupados em blocos, com a proposição de nove modelos de regressão com dados em painel, dos quais oito corroboram o fenômeno cost stickiness. Ainda, os resultados indicam similaridade com o fenômeno flypaper, típico do setor público, que utiliza parte da receita para o cálculo da assimetria, em que, dos três tipos de análises realizadas, a utilização da receita vinculada é a que resultou em maior sticky. Por fim, oferece subsídios para a aplicação da TCS ao setor público, mesmo se tratando de um fenômeno típico de entidades com fins lucrativos, e conclui que, com a utilização da receita fracionada (assim como no fênomeno flypaper) para os governos locais de Santa Catarina, o comportamento dos custos aparenta maior grudência.

Palavras-Chave: Comportamento dos custos. Cost stickiness. Assimetria dos custos. Custos públicos. Governo local.

Editado em português e inglês. Versão original em Português.

Recebido em 4/2/2021. Revisado em 19/5/2021. Aceito em 25/5/2021 pelos Prof. Dr. Sérgio Murilo Petri (Editor-Chefe) e Prof. Dr. Sandro Vieira Soares (Editor Adjunto). Publicado em 25/6/2021.

Copyright ( 92021 RCCC. Todos os direitos reservados. É permitida a citação de parte de artigos sem autorização prévia, desde que identificada a fonte. 


\begin{abstract}
Asymmetric cost behavior took a new approach, starting in 2003, with the emergence of the Cost Asymmetric cost behavior took a new approach, starting in 2003, with the emergence of the Cost Stickiness Theory (CST) and, since it is something recent, there are still doubts regarding its application in the public sector. In this sense, this study aims to analyze the behavior of costs in local governments in Santa Catarina, from the cost stickiness perspective. This is an empirical, quantitative, and documentary study that uses the population of 295 municipalities in Santa Catarina during the 20-year period, whose transposition of the analysis model was adapted for the public sector. We grouped the costs in blocks, with the proposition of nine regression models with panel data, of which, eight corroborate the cost stickiness phenomenon. Still, the results indicate similarity with the flypaper phenomenon, typical of the public sector, which uses part of the recipe to calculate the asymmetry, in which of the three types of analyzes performed, the use of the recipe is linked to the one that resulted in the highest sticky. Finally, it offers subsidies for the application of CST to the public sector, even in the case of a typical phenomenon of for-profit entities, and concludes that, with the use of fractional revenue (as well as in the phenomenal flypaper) for local governments of Santa Catarina, the behavior of costs appears to be stickier.
\end{abstract}

Keywords: Cost behavior. Cost stickiness. Asymmetry of costs. Public costs. Local government.

\title{
1 INTRODUÇÃO
}

A prática governamental de limitar os gastos públicos às receitas resultou na consolidação literária do equilíbrio orçamentário, em meados de 1850 , que permanece na literatura e nas normas jurídicas que regem as contas públicas atualmente (Santos, Ribeiro, Ribeiro \& Pinto, 2017). Contudo, a escassez de recursos tem preocupado gestores e pesquisadores, e levado ao aprimoramento de procedimentos e teorias sobre as questões que envolvem os custos. Em 1937, a Teoria da Firma, do economista Ronald Coase, deu início a uma nova dimensão nas pesquisas sobre gestão, com consequências nos procedimentos e métodos de custos, na maioria voltadas ao setor privado, com foco na maximização do lucro.

Tradicionalmente, em pesquisas sobre comportamento de custos, o pressuposto é o comportamento simétrico dos custos em relação às receitas, isto é, as receitas e os custos aumentam ou diminuem na mesma proporção, enquanto o assimétrico ocorre quando não há a mesma proporção. Porém as discussões se ampliaram com contribuições teóricas e empíricas sobre o assunto de tal modo que, hoje, a assimetria de custos já é reconhecida na literatura e deu origem à mais nova teoria contábil sobre comportamento de custos, a Teoria dos Cost Stickiness (TCS), baseada no trabalho seminal de Anderson, Banker e Janakiraman (2003), que ofereceram uma explicação matemática para o fenômeno.

A TCS pressupõe que os custos aumentam, normalmente, quando há crescimento das atividades produtivas, mas não diminuem na mesma proporção quando tais atividades decrescem, e utiliza como base de cálculo as receitas e o custo total (incluindo-se as despesas). No Brasil, o modelo recebeu importantes contribuições, sobretudo de Richartz e Borgert (2020). Contudo a referida teoria ainda se encontra em fase de consolidação internacional.

No âmbito público, a questão dos custos ganhou destaque nas últimas décadas, mas existem várias lacunas de pesquisa ligadas às peculiaridades do setor (Bracci, Humphrey, Moll, \& Steccolini, 2015; Helden \& Uddin, 2016), uma delas é a relacionada ao comportamento dos custos públicos. No geral, os estudos sobre a TCS utilizam amostras empresariais, de entidades com fins lucrativos. Todavia Hosomi e Nagasawa (2018) afirmam que não pode ser aplicada ao setor público puro, principalmente devido ao caráter sem fins lucrativos dos governos. Assim, a 
literatura da TCS ainda é incipiente particularmente para o setor público, e o fenômeno cost stickiness ainda carece de adequação às contas públicas.

Para efeitos da TCS, os custos empresariais são considerados em sua totalidade. Contudo, para fins desta pesquisa, que adapta o modelo de comportamento ao setor público, são consideradas como custos todas as despesas orçamentárias executadas. Neste sentido, períodos sucessivos de equilíbrio orçamentário (medido pelo resultado do período) pressupõem um comportamento simétrico (medido pela variação entre períodos) no comportamento dos custos. Apesar de a maioria dos países estabelecer a obrigatoriedade do orçamento equilibrado no setor público, ao usar como preceito o equilíbrio das finanças públicas, há indícios de que o mesmo nem sempre ocorre, o que coloca em dúvida o suposto comportamento simétrico.

Indiretamente, pesquisas revelam variações não proporcionais das despesas públicas diante do aumento ou redução das receitas como, por exemplo, em estudos sobre o efeito flypaper (Gamkhar \& Oates, 1996; Volden, 1999; Kandil, 2001; Levaggi \& Zanolla, 2003; LagoPeñas, 2008; Sakurai, 2013; Gennari \& Messina, 2014), que mede se as despesas públicas locais são igualmente sensíveis a aumentos de transferências intergovernamentais e renda pessoal (Levaggi \& Zanolla, 2003; Lago-Peñas, 2008; Gennari \& Messina, 2014). Apesar de o comportamento flypaper medir simetria ou assimetria de contas públicas específicas, concomitantemente, abre a possibilidade da TCS também ser aplicável ao setor público, visto que, de acordo com o modelo proposto por Anderson et al. (2003), esperam-se variações não proporcionais dos custos diante de aumento ou redução das receitas.

Esses indícios podem ser observados no trabalho de Lago-Peñas (2008), em que fatores financeiros e políticos explicam o comportamento diferenciado das despesas com a proximidade de períodos eleitorais. Ainda, ideologias partidárias ou nível de arrecadação tributária podem determinar a forma de gerenciamento das contas e, por consequência, a variação entre receitas e despesas. Para Sakurai (2013), se a economia está em expansão, a produção interna aumenta e a arrecadação tributária cresce, todavia, em momentos de recessão econômica, a redução de despesas não é tão simples, pois as necessidades públicas permanecem crescentes, embora a verba seja limitada. Exemplo disso é a atual situação mundial, em função da pandemia do coronavírus, que tem levado a excessivos gastos públicos e à redução da arrecadação.

Considerando-se o modelo de federalismo brasileiro, Suzart, Zuccolotto e Rocha (2018) afirmam que as transferências intergovernamentais, em média, chegam a $86 \%$ do total da receita em 4.203 municípios brasileiros. Portanto há dependência local das transferências governamentais que podem gerar riscos de déficits em situações que levam os governos centrais a reduzirem repasses. De qualquer modo, prevalece a visão teórica de que despesas e receitas públicas são equilibradas e, por consequência, levam a um comportamento simétrico dos custos entre períodos. Apesar dos indícios, a assimetria no comportamento dos custos públicos, pela abordagem cost stickiness, ainda carece de comprovação empírica.

Com base nessa perspectiva, que ainda permanece obscura na literatura do setor público, a questão-problema que norteia esta pesquisa é: como se comportam os custos nos governos locais de Santa Catarina, na perspectiva dos cost stickiness? E, para responder esta questão, objetiva-se analisar o comportamento dos custos nos governos locais de Santa Catarina, na perspectiva dos cost stickiness.

Assim, com base nos estudos anteriormente mencionados sobre o efeito flypaper no setor público, que sugerem a existência da assimetria de custos com base em abordagem teórica, tomando-se apenas parte da receita arrecada para efeitos de análise, esta pesquisa corrige algumas distorções dos modelos estatísticos utilizados para adaptar à modelagem da TCS. Nesse sentido, são propostos e rodados modelos que melhor se adaptam às características do setor público.

A pesquisa se justifica pela relevância na identificação do comportamento de custos em governos locais, já que a literatura ainda carece de amadurecimento. Para Wu, Young, Yu e 
Hsu (2020), a temática é atual e a escassez de literatura é um obstáculo para pesquisas sobre comportamento de custos no setor público. Ainda, segundo Hosomi e Nagasawa (2018), não há comprovação do fenômeno cost stickiness no setor público puro. Portanto a principal contribuição desta pesquisa é quanto à comprovação do fenômeno cost stickiness no setor público puro, mesmo que analisado em grupos de contas.

Vale destacar que o método estatístico do flypaper é específico para o setor público, enquanto a abordagem do comportamento cost stickiness foi, inicialmente, desenvolvida com base em amostras empresariais. Portanto esta pesquisa adapta o modelo da TCS às peculiaridades do setor público, de modo que a essência da perspectiva de Anderson et al. (2003) e os elementos já contemplados na literatura não sejam descaracterizados.

\section{FUNDAMENTAÇÃO TEÓRICA}

Esta pesquisa trata da temática comportamento dos custos, que considera a variação entre receitas e custos totais para períodos distintos. Neste sentido, a abordagem sobre comportamento de custos assimétricos desenvolvida por Anderson et al. (2003), que deu origem à TCS, pressupõe que os custos aumentam quando a receita aumenta, mas não diminuem na mesma proporção quando há diminuição na receita (sticky cost). Ou seja, há uma "grudência" que não permite que a variação dos custos acompanhe a variação das receitas. Vale destacar que o inverso também é verdadeiro (comportamento anti-sticky). Em resumo, o efeito assimétrico sob essa perspectiva, na literatura internacional, é denominado de cost stickiness.

A abordagem da TCS de Anderson et al. (2003) foi replicada em empresas do Brasil por Medeiros, Costa e Silva (2005), que também comprovaram o fenômeno. Contudo Richartz e Borgert (2020) contribuíram com a teoria ao identificarem 11 fatores que explicam os costs stickiness, em função de características empresariais e de sua evolução no tempo. Cabe destacar que o presente estudo aborda a TCS aplicada ao setor público, enquanto a literatura, no geral, volta-se mais para observações do setor privado.

As adaptações de técnicas, métodos e teorias advindas de outras áreas do conhecimento, devido à diversidade de conceitos e distintos processos de contabilização do setor, precisam de um olhar diferenciado para aplicação no setor público (Suzart, 2012). Os efeitos assimétricos de despesas públicas foram pesquisados em relação ao fenômeno econômico denominado de comportamento ou efeito flypaper. Desta forma, buscam-se evidências de que as variações das transferências exercem sobre as despesas o mesmo efeito, ou efeito proporcionalmente diferente, do que seria observado caso a renda privada variasse na mesma dimensão.

Sobre as pesquisas no âmbito do setor público, a assimetria foi medida com foco no comportamento ou efeito flypaper, o que limita os achados às transferências recebidas de outra esfera de governo. Por exemplo, Gamkhar e Oates (1996) verificaram as despesas municipais e estaduais nos Estados Unidos em resposta às variações em transferências governamentais. Volden (1999) analisou os gastos assistenciais em estados americanos diante das transferências governamentais recebidas, enquanto Levaggi e Zanola (2003) analisaram o comportamento das despesas com saúde em função das receitas de transferências em governos locais da Itália. Já Lago-Peñas (2008) estudou os efeitos assimétricos em municípios espanhóis, em despesas de capital e correntes. Sakurai (2013) investigou o comportamento assimétrico em municípios brasileiros, analisando totais e separadamente por despesas, e receitas correntes e de capital; Gennari e Messina (2014) estudaram o mesmo comportamento em governos locais italianos pelo total das despesas. Assim, a Tabela 1 sintetiza os estudos comentados e sugere o comportamento encontrado associando o efeito flypaper ao efeito cost stikiness. 
Tabela 1

\section{Estudos anteriores}

\begin{tabular}{|c|c|c|c|c|c|c|}
\hline Autores & País & Ano & Amostra & Receitas & Despesas & $\begin{array}{c}\text { Sugestão de } \\
\text { comportamento }\end{array}$ \\
\hline $\begin{array}{l}\text { Gamkhar e } \\
\text { Oates }\end{array}$ & EUA & 1996 & $\begin{array}{l}\text { Municípios e } \\
\text { estados } \\
\text { americanos }\end{array}$ & Transferências & Totais & Simétrico \\
\hline Volden & EUA & 1999 & $\begin{array}{c}\text { Estados } \\
\text { americanos }\end{array}$ & $\begin{array}{l}\text { Transferências } \\
\text { vinculadas a } \\
\text { benefícios } \\
\text { assistenciais }\end{array}$ & $\begin{array}{l}\text { Vinculadas a } \\
\text { benefícios } \\
\text { assistenciais }\end{array}$ & Assimétrico \\
\hline $\begin{array}{l}\text { Anderson, } \\
\text { Banker e } \\
\text { Janakiraman }\end{array}$ & EUA & 2003 & $\begin{array}{c}\text { Empresas } \\
\text { americanas }\end{array}$ & Totais & $\begin{array}{l}\text { Vendas, gerais e } \\
\text { administrativas }\end{array}$ & $\begin{array}{c}\text { Assimétrico (cost } \\
\text { sticky) }\end{array}$ \\
\hline $\begin{array}{l}\text { Levaggi e } \\
\text { Zanola }\end{array}$ & Itália & 2003 & $\begin{array}{c}\text { Governos } \\
\text { locais italianos }\end{array}$ & Transferências & $\begin{array}{l}\text { Totais e por } \\
\text { categoria } \\
\text { econômica }\end{array}$ & Assimétrico \\
\hline $\begin{array}{l}\text { Medeiros, } \\
\text { Costa e Silva }\end{array}$ & Brasil & 2005 & $\begin{array}{l}\text { Empresas } \\
\text { brasileiras }\end{array}$ & Totais & $\begin{array}{l}\text { Vendas, gerais e } \\
\text { administrativas }\end{array}$ & $\begin{array}{c}\text { Assimétrico (cost } \\
\text { sticky) }\end{array}$ \\
\hline Lago-Peñas & Espanha & 2008 & $\begin{array}{l}\text { Municípios } \\
\text { espanhóis }\end{array}$ & Transferências & Totais & Assimétrico \\
\hline Sakurai & Brasil & 2013 & $\begin{array}{l}\text { Municípios } \\
\text { brasileiros }\end{array}$ & Transferências & $\begin{array}{l}\text { Totais e por } \\
\text { componentes } \\
\text { específicos }\end{array}$ & $\begin{array}{l}\text { Simétrico no total; } \\
\text { assimétrico em } \\
\text { componentes } \\
\text { específicos }\end{array}$ \\
\hline $\begin{array}{l}\text { Gennari e } \\
\text { Messina }\end{array}$ & Itália & 2014 & $\begin{array}{c}\text { Governos } \\
\text { locais italianos }\end{array}$ & Transferências & Totais & Simétrico \\
\hline $\begin{array}{l}\text { Hosomi e } \\
\text { Nagasawa }\end{array}$ & Japão & 2018 & $\begin{array}{c}\text { Empresas } \\
\text { públicas locais }\end{array}$ & $\begin{array}{l}\text { Receita } \\
\text { operacional } \\
\text { (públicas e } \\
\text { privadas) }\end{array}$ & $\begin{array}{c}\text { Despesa } \\
\text { operacional }\end{array}$ & $\begin{array}{c}\text { Assimétrico (cost } \\
\text { anti-sticky) }\end{array}$ \\
\hline $\begin{array}{l}\text { Richartz e } \\
\text { Borgert }\end{array}$ & Brasil & 2020 & $\begin{array}{l}\text { Empresas } \\
\text { brasileiras }\end{array}$ & Totais & $\begin{array}{l}\text { Vendas, gerais e } \\
\text { administrativas }\end{array}$ & $\begin{array}{c}\text { Assimétrico, (cost } \\
\text { sticky) }\end{array}$ \\
\hline
\end{tabular}

Fonte: Elaborado pelos autores (2021).

Como se pode observar, no setor público não há um consenso acerca das evidências de efeitos assimétricos no comportamento dos custos, principalmente porque, ao analisar receitas e despesas totais, o comportamento é simétrico, por força na normatização da área, que estabelece o orçamento equilibrado. Os estudos em programas de governo específicos se limitam ao efeito flypaper, o que limita os achados às ações de governo escolhidas e aos métodos utilizados. Apenas o estudo de Hosomi e Nagasawa (2018) aplica a TCS ao analisar empresas públicas locais japonesas (empresas privadas com autorização e subsídio do governo para fornecer serviços públicos), contudo os autores informam que essas empresas seguem as regras contábeis privadas e que, se fossem puramente públicas, não seria possível aplicar a TCS. Assim, os resultados até então encontrados para o comportamento dos custos no setor público não são conclusivos e não seguem a abordagem da TCS.

\section{PROCEDIMENTOS METODOLÓGICOS}

Esta pesquisa foi desenvolvida mediante análise de regressão com dados em painel, que teve como base um conjunto de municípios (cross-section) observados ao longo do tempo (séries temporais). A população, objeto de estudo, é representada pelos 295 municípios do estado de Santa Catarina, localizado na região sul do Brasil, no período de 1999 a 2018, ou seja, os últimos 20 anos de dados publicados. Todavia destaca-se a ausência de dados pontuais inerentes a três 
municípios: receitas e despesas relativas a Flor do Sertão, em 2012, Alfredo Wagner e Santo Amaro da Imperatriz, em 2014. Ademais, até 2012, Santa Catarina possuía 293 municípios e, a partir de 2013, surgiram os municípios de Balneário Rincão e Pescaria Brava.

Os dados foram solicitados via sistema de ouvidoria e fornecidos pelo Tribunal de Contas do Estado de Santa Catarina (TCE/SC). Algumas informações faltantes foram coletadas manualmente no portal de divulgação das contas públicas deste mesmo órgão. Com vistas a minimizar os efeitos inflacionários, os dados foram ajustados pelo Índice Nacional de Preços ao Consumidor Amplo (IPCA), disponível no sítio eletrônico do Instituto Brasileiro de Geografia e Estatística (IBGE, 2019).

A análise multivariada dos dados seguiu a metodologia proposta por Anderson et al. (2003) e adotada no Brasil por Medeiros et al. (2005) e Richartz e Borgert (2020), já consolidada em termos literários. Embora o modelo tenha enfoque em empresas privadas, optou-se por utilizá-lo no âmbito do setor público, uma vez que pesquisas anteriores voltadas ao setor público propõem modelos econométricos que analisam o comportamento das despesas apenas em relação às transferências governamentais (comportamento flypaper).

Para efeitos desta pesquisa, os custos do modelo de Anderson et al. (2003), representados pelo total de custos e despesas apropriados no demonstrativo contábil do setor privado, foram adaptados para o setor público, considerados como custos do modelo todas as despesas públicas orçamentárias executadas (liquidadas no período).

Contudo reconhecem-se as evidentes diferenças entre o setor público e o privado, de modo que a análise dos resultados obtidos é discutida no âmbito público. Posto isso, o modelo de regressão é utilizado para verificar como as despesas públicas se comportam diante das variações nas receitas públicas, com descrição dos respectivo período. Sua especificação é representada como:

$$
\left.\log \left[\frac{\text { despesas }_{i, t}}{\text { despesas }_{i, t-1}}\right\rceil=\beta_{0}+\beta_{1} \log \left\lceil\frac{\text { receitas }_{i, t}}{\text { receitas }_{i, t-1}}\right\rceil+\beta_{2} \text { Dummy }_{i, t} * \log \mid \frac{\text { receitas }_{i, t}}{\text { receitas }_{i, t-1}}\right\rceil+\varepsilon_{i, t}
$$

As despesas representam a variável dependente e as receitas as independentes, $i$ corresponde a cada município observado, $t$ corresponde a cada ano, $t-1$ indica o período anterior, e $\varepsilon$ denota o componente de erro da equação. A variável dummy assume o valor 1 quando há queda na receita entre o ano anterior e o ano de referência $\left(\right.$ receita $_{i, t}<$ receita $_{i, t-1}$ ), e o valor 0 em caso de aumento.

O coeficiente $\beta_{1}$ mede o percentual de aumento nas despesas em relação ao aumento de $1 \%$ nas receitas. No caso de redução das receitas, a variável dummy passa a integrar a equação e, desse modo, o percentual de redução das despesas em relação à diminuição de $1 \%$ nas receitas é medida pelo somatório dos coeficientes $\beta_{1}$ e $\beta_{2}$. De acordo com o modelo, nas despesas assimétricas, a variação em relação ao aumento das receitas deve ser maior que a variação em relação à diminuição das receitas, acarretando em $\beta_{1}>0, \beta_{2}<0$ e $\beta_{1}+\beta_{2}<1$ (Medeiros et al., 2003).

A especificação linear em logaritmo repara os efeitos das distâncias entre valores observados, ou seja, aumenta as distâncias entre valores pequenos e reduz as distâncias entre valores grandes (Barbetta, 2011). Assim, a comparabilidade das variáveis entre os municípios se torna possível, uma vez que os efeitos da diversidade de tamanho entre eles são amenizados com a transformação logarítmica.

Quanto aos modelos de regressão, os testes de Breusch-Pagan, F de Chow e de Hausman indicam como o estimador mais consistente o de intercepto comum ou pooled regression. Posteriormente foram testadas a autocorrelação, via teste proposto por Wooldridge, e a heterocedasticidade pelo teste de Wald, as quais foram confirmadas para os modelos. Embora a análise gráfica tenha indicado uma distribuição homogênea no gráfico dos resíduos versus 
predição linear, os modelos foram reestimados com erros-padrão robustos a fim de torná-los mais acurados. Além disso, destaca-se que os testes de normalidade rejeitaram a hipótese nula de distribuição normal dos resíduos. Considerando-se, contudo, o tamanho da amostra analisada, assume-se a normalidade assintótica, respaldada no teorema do limite central (Gujarati, 2006).

Quanto aos procedimentos de pesquisa, analisou-se a variação das despesas públicas em função da variação nas receitas públicas. O cálculo utilizando o valor total é típico da TCS, enquanto o cálculo utilizando grupos de receitas é típico do flypaper. A investigação da assimetria foi feita em duas propostas, a primeira considera as despesas totais e a segunda, o agrupamento de componentes.

Tabela 2

Procedimentos de análise do comportamento das despesas totais em relação às receitas

\begin{tabular}{l|l}
\hline Análise 1 & Comportamento assimétrico das despesas totais em relação às receitas totais. \\
\hline Análise 2 & $\begin{array}{l}\text { Comportamento assimétrico das despesas totais em relação às receitas por origens de recursos } \\
(2.1 \text { - receitas próprias e } 2.2 \text { - transferências governamentais). }\end{array}$ \\
\hline
\end{tabular}

Fonte: Elaborado pelos autores (2021).

A segunda proposta compreende a análise do comportamento assimétrico em relação às despesas da classificação funcional, motivada pelos estudos anteriores que trouxeram indícios de assimetria nos custos públicos (Tabela 1). Estas despesas são estabelecidas na Portaria MOG $\mathrm{n}^{\circ}$ 42, de 14 de abril de 1999, a qual teve algumas classificações atualizadas em 2012 (Portaria MOG nº 42, 1999). Segundo esta norma jurídica, a função é o maior nível de agregação das áreas de competência no setor público.

Ao todo, a classificação contábil funcional especifica 28 funções. No entanto observou-se que, para a amostra estudada, determinadas funções representam menos de $0,5 \%$ das despesas totais. Além disso, observou-se que algumas descrições de funções apresentaram modificações ao longo do período analisado. Assim, para tornar a análise do comportamento das despesas mais representativa, as funções foram agrupadas em 7 grupos, de acordo com as suas similaridades. $\mathrm{O}$ grupo denominado "Demais Funções" compreende as funções que representam menos de 5\% das despesas totais do período.

Tabela 3

Agrupamento das despesas em "Grupos de Funções"

\begin{tabular}{|c|c|c|c|}
\hline Função & Grupo & Função & Grupo \\
\hline $\begin{array}{l}\text { Administração } \\
\text { Administração e Planejamento } \\
\text { Comunicações }\end{array}$ & $\begin{array}{l}\text { Administração e } \\
\text { Comunicações }\end{array}$ & \multirow{2}{*}{$\begin{array}{l}\text { Defesa Nacional } \\
\text { Defesa Nacional e Segurança } \\
\text { Pública } \\
\text { Segurança Pública } \\
\text { Relações Exteriores }\end{array}$} & \multirow{2}{*}{$\begin{array}{c}\text { Defesa } \\
\text { Nacional, } \\
\text { Segurança } \\
\text { Pública e } \\
\text { Relações } \\
\text { Exteriores } \\
\end{array}$} \\
\hline $\begin{array}{l}\text { Assistência e Previdência } \\
\text { Assistência Social }\end{array}$ & \multirow{2}{*}{$\begin{array}{l}\text { Assistência e } \\
\text { Previdência } \\
\text { Social }\end{array}$} & & \\
\hline $\begin{array}{l}\text { Previdência Social } \\
\text { Trabalho }\end{array}$ & & \multirow{4}{*}{$\begin{array}{l}\text { Agricultura } \\
\text { Organização Agrária } \\
\text { Gestão Ambiental } \\
\text { Energia } \\
\text { Energia e Recursos Minerais } \\
\text { Direitos da Cidadania } \\
\text { Encargos Especiais } \\
\text { Essencial à Justiça } \\
\text { Fundef } \\
\text { Indústria } \\
\text { Indústria, Comércio e Serviços }\end{array}$} & \multirow{4}{*}{$\begin{array}{l}\text { Demais } \\
\text { Funções }\end{array}$} \\
\hline $\begin{array}{l}\text { Educação } \\
\text { Cultura } \\
\text { Educação e Cultura } \\
\text { Ciência e Tecnologia } \\
\text { Desporto e Lazer } \\
\end{array}$ & $\begin{array}{l}\text { Educação e } \\
\text { Cultura }\end{array}$ & & \\
\hline $\begin{array}{l}\text { Saúde } \\
\text { Saúde e Saneamento } \\
\text { Saneamento } \\
\end{array}$ & $\begin{array}{c}\text { Saúde e } \\
\text { Saneamento }\end{array}$ & & \\
\hline Habitação & Habitação, & & \\
\hline
\end{tabular}




\begin{tabular}{|c|c|c|}
\hline $\begin{array}{l}\text { Habitação e Urbanismo } \\
\text { Transporte } \\
\text { Urbanismo } \\
\text { Desenvolvimento Regional } \\
\text { Comércio e Servicos }\end{array}$ & $\begin{array}{l}\text { Transporte, } \\
\text { Urbanismo, } \\
\text { Comércio e } \\
\text { Serviços }\end{array}$ & $\begin{array}{l}\text { Judiciária } \\
\text { Legislativa } \\
\text { Reserva Contingência }\end{array}$ \\
\hline
\end{tabular}

Fonte: Elaborado pelos autores (2021).

Procedimento similar de agrupamento de despesas foi realizado por Sakurai (2013), discriminando-as em despesas correntes, investimentos e social. Nesse sentido, pode-se entender como uma das contribuições deste artigo a análise dos dados discriminados nas classes de despesas e de receitas especificadas, agrupadas em distintas categorias. A utilização da receita parcial, para maior representatividade dos resultados, é algo típico das análises do fenômeno flypaper, que é utilizado para o setor público. Neste estudo, adaptou-se a fórmula da TCS ao utilizar partes das despesas públicas para representar os custos. Assim, o procedimento de análise do comportamento das despesas por grupo de funções é apresentado como uma terceira proposta, conforme a Tabela 4.

Tabela 4 Procedimentos de análise do comportamento das despesas em relação às receitas após
agrupamento das Funções

Análise 3 Comportamento assimétrico das despesas por Grupos de Funções em relação às receitas totais.

Fonte: Elaborado pelos autores (2021).

No total, foram estimadas nove regressões com base no modelo apresentado. Destaca-se que, para todas as estimações, foram realizados os testes comentados anteriormente. Assim, o melhor modelo apontado foi o de intercepto comum ou pooled regression para todas as regressões estimadas. A seguir, apresentam-se os resultados e considerações acerca dos municípios catarinenses e do comportamento das despesas públicas no período.

\section{RESULTADOS}

No período analisado de 20 anos (1999-2018), ocorreu crescimento tanto nas receitas quanto nas despesas (na ordem de 348\%), como era de se esperar, uma vez que se pressupõe, também, crescimento populacional e econômico no período. As receitas próprias aumentaram $498 \%$, ao passo que as receitas de transferência cresceram $289 \%$, o que revela, se comparado ao estudo sobre flypaper de Sakurai (2013), um menor percentual de dependência da União e estado, na receita dos municípios.

Quanto aos Grupos de Funções (Figura 1), conforme especificado anteriormente, é possível verificar que alguns grupos são mais representativos que outros. $\mathrm{O}$ grupo que envolve despesas com Defesa Nacional, Segurança Pública e Relações Exteriores não teve gastos registrados, visto que não são despesas típicas de municípios. A representatividade de receitas e despesas, dentro do orçamento público executado, já é suficiente para perceber que a assimetria com base, apenas nas receitas de transferências (Gamkhar \& Oates, 1996; Volden, 1999; Levaggi \& Zanola, 2003; Lago-Peñas, 2008; Sakurai, 2013; Gennari \& Messina, 2014), pode distorcer o modelo estatístico de Anderson et al. (2003), já que este considera os totais. 


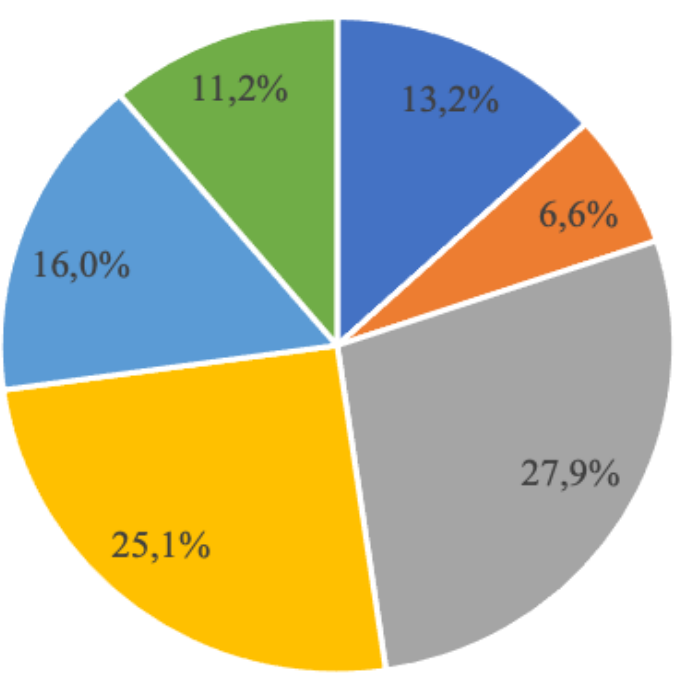

- Admin istração e Comunicações

- Assistência e Previdência Social

- Educação e Cultura

" Saúde e Saneamento

- Habitação, Transporte, Urbanismo, Comércio e Serviços

- Demais Funções

Figura 1. Despesas por grupo de função em relação às despesas totais Fonte: Elaborado pelos autores (2021).

A Tabela 5 apresenta as estatísticas das estimações dos modelos de regressão, cujos resultados da pesquisa foram obtidos conforme definido nos procedimentos metodológicos. São apresentados os coeficientes $\beta_{0}, \beta_{1}$ e $\beta_{2}$, os resultados das estatísticas de Wald chi ${ }^{2}$, os coeficientes de correlação $\mathrm{R}^{2}$ e o número de observações. As análises 1 e 2 correspondem, respectivamente, às variações na despesa total em relação às variações nas receitas totais (1), próprias (2.1) e transferências governamentais (2.2).

\section{Tabela 5}

\section{Coeficientes estimados de variação para Análises 1 e 2}

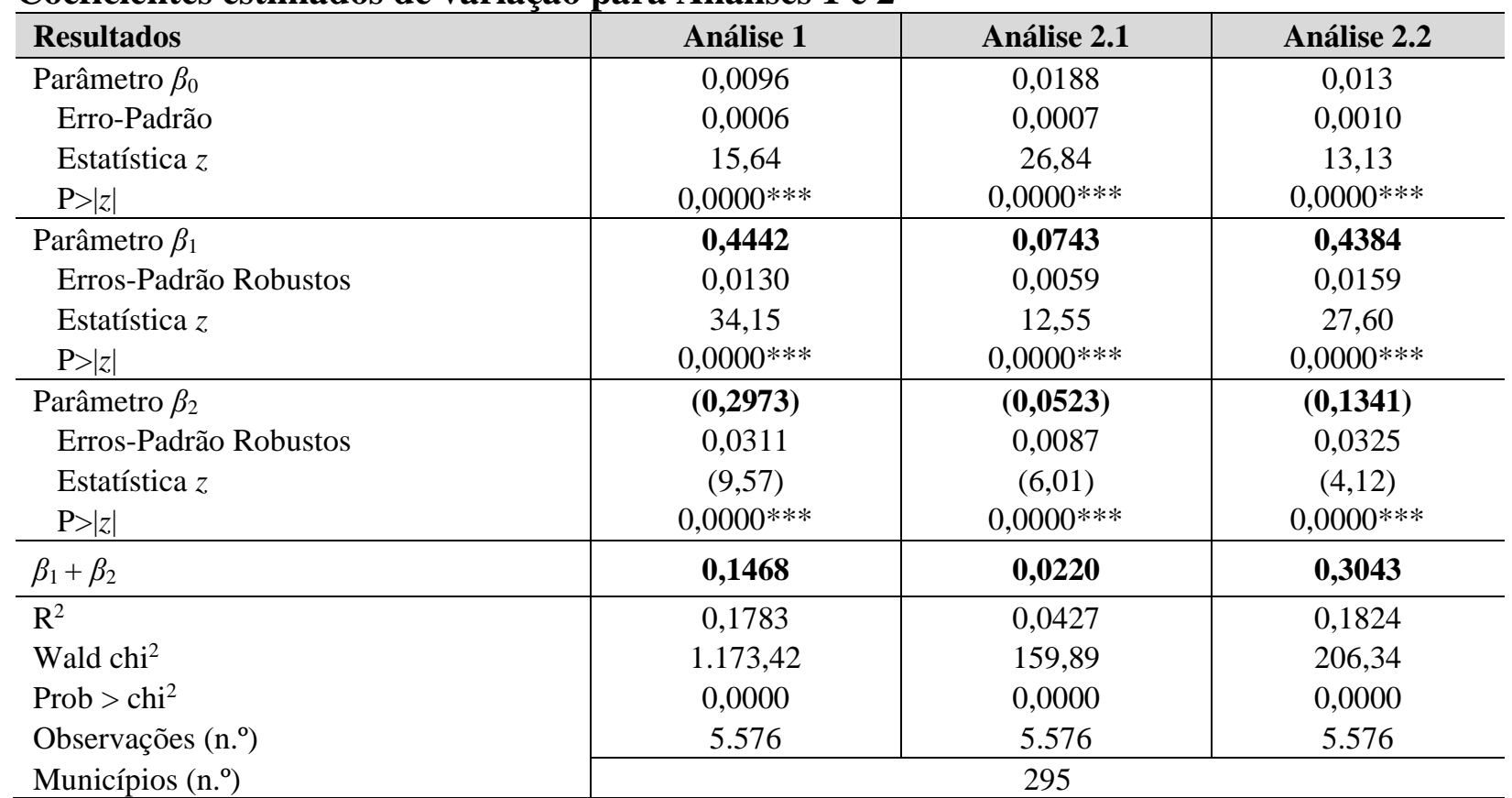

Nota. *** denota significância estatística a $1 \%$.

Fonte: Elaborado pelos autores (2021). 
Conforme prevê o modelo de Anderson et al. (2003), verifica-se que os sinais dos coeficientes indicam assimetria $\left(\beta_{1}>0, \beta_{2}<0\right.$ e $\left.\beta_{1}+\beta_{2}<1\right)$. Dessa forma, pode-se dizer que a proporção do aumento das despesas em função do aumento nas receitas é maior que a proporção da redução das despesas em função de diminuição equivalente nas receitas. Ou seja, em caso de redução nas receitas públicas, as despesas não reduzem na mesma proporção em que aumentam em caso de elevação nas mesmas receitas. As estatísticas foram significantes a $1 \%$ para as quatro análises.

$\mathrm{Na}$ análise 1, que indica variação das despesas totais em relação às receitas totais, o coeficiente $\beta_{1}$ apresentou valor de 0,4442 . Logo, as despesas totais aumentaram $0,4442 \%$ diante do aumento de $1 \%$ nas receitas totais. Somando-se $\beta_{1}$ com $\beta_{2}$ se obtém 0,1468 , conforme demonstrado na Tabela 5. Assim, as despesas reduziram $0,1468 \%$ em relação à diminuição de $1 \%$ nas receitas totais. Observa-se que a variação foi assimétrica, uma vez que a redução das despesas dos municípios não acompanhou, na mesma proporção, a diminuição nas receitas.

As análises 2.1 e 2.2, que investigaram o comportamento das despesas totais em relação às receitas próprias e às transferências governamentais, demonstraram que o efeito assimétrico também se confirma quando as receitas são analisadas por origem de recursos. No caso das transferências (análise 2.2), cada $1 \%$ de aumento acarretou no crescimento de $0,4384 \%$ nas despesas, ao passo que a redução na mesma proporção diminuiu apenas $0,3043 \%$ destas despesas. Considerando-se a dependência que os municípios ainda possuem sobre as transferências da União e estados, momentos de baixa na economia e, consequentemente, redução na arrecadação de recursos, podem levar os entes públicos ao desequilíbrio orçamentário, uma vez que a redução em sua estrutura de custos e despesas não consegue alcançar a baixa nas receitas.

Portanto a análise do comportamento dos custos mediate a variação das receitas pode ser de utilidade para os gestores dos municípios, como forma de entender a importância do orçamento público como ferramenta de gestão que, se bem planejada e executada, ainda pode prever reduções futuras de receitas e adaptar os gastos públicos a tais situações, evitando-se, assim, políticas de austeridade. Ademais, a sociedade também pode se beneficiar de tal análise, seja diretamente ou indiretamente, como forma de averiguar a eficiência no uso dos recursos públicos.

Paralelamente à abordagem costs stickiness, os resultados corroboram pesquisas sobre flypaper de Volden (1999), Levaggi e Zanola (2003) e Lago-Peñas (2008), que verificaram impacto assimétrico das transferências governamentais sobre as despesas em estados americanos, governos locais italianos e espanhóis, sucessivamente. Por sua vez, Gamkhar e Oates (1996), Gennari e Messina (2014) e Sakurai (2013) não obtiveram evidências suficientes para confirmar a assimetria no comportamento flypaper em estados americanos, governos locais italianos e brasileiros.

A Tabela 6 apresenta as estatísticas das estimações dos modelos de regressão, cujos resultados da pesquisa foram obtidos conforme definido nos procedimentos metodológicos. A análise 3 corresponde às variações por grupo de despesas em relação às variações nas receitas totais.

Tabela 6

\section{Coeficientes estimados de variação para Análise 3 - Grupos de Funções}

\begin{tabular}{l|c|c|c|c|c|c}
\hline Resultados & Grupo 1 & Grupo 2 & Grupo 3 & Grupo 4 & Grupo 5 & Grupo 6 \\
\hline Parâmetro $\beta_{0}$ & 0,0019 & 0,0209 & 0,0010 & 0,0287 & $(0,0090)$ & 0,0254 \\
Erro-Padrão & 0,0018 & 0,0030 & 0,0038 & 0,0030 & 0,0023 & 0,016 \\
Estatística $z$ & 1,09 & 7,08 & 0,26 & 9,49 & 3,86 & 16,24 \\
$\mathrm{P}>|z|$ & 0,2770 & $0,0000^{* * *}$ & 0,7930 & $0,0000^{* * *}$ & $0,0000^{* * *}$ & $0,0000^{* * *}$ \\
\hline Parâmetro $\beta_{1}$ & $\mathbf{0 , 2 5 0 9}$ & $\mathbf{0 , 4 0 3 8}$ & $\mathbf{0 , 5 3 5 6}$ & $\mathbf{0 , 5 3 8 5}$ & $\mathbf{0 , 8 1 6 8}$ & $\mathbf{0 , 1 1 5 8}$
\end{tabular}




\begin{tabular}{|c|c|c|c|c|c|c|}
\hline Erros-Padrão Robustos & 0,0390 & 0,0523 & 0,1176 & 0,0635 & 0,0477 & 0,0300 \\
\hline Estatística $z$ & 6,43 & 7,71 & 4,56 & 8,48 & 17,11 & 3,86 \\
\hline $\mathrm{P}>|z|$ & $0,0000 * * *$ & $0,0000 * * *$ & $0,0000 * * *$ & $0,0000 * * *$ & $0,0000 * * *$ & $0,0000 * * *$ \\
\hline Parâmetro $\beta_{2}$ & $(0,2899)$ & $(0,4831)$ & $(0,5014)$ & $(0,3825)$ & $(0,4136)$ & $\mathbf{0 , 0 3 3 7}$ \\
\hline Erros-Padrão Robustos & 0,0591 & 0,1066 & 0,0795 & 0,1154 & 0,1115 & 0,0634 \\
\hline Estatística $z$ & $(4,91)$ & $(4,53)$ & $(6,31)$ & $(3,32)$ & $(3,71)$ & 0,53 \\
\hline $\mathrm{P}>|z|$ & $0,0000 * * *$ & $0,0000 * * *$ & $0,0000 * * *$ & $0,0010 * * *$ & $0,0000 * * *$ & 0,5950 \\
\hline$\beta_{1}+\beta_{2}$ & $(0,0390)$ & $(0,0793)$ & 0,0342 & 0,1560 & 0,4032 & 0,1495 \\
\hline $\mathrm{R}^{2}$ & 0,0077 & 0,0084 & 0,0123 & 0,0122 & 0,0527 & 0,0047 \\
\hline Wald chi ${ }^{2}$ & 41,45 & 59,50 & 48,52 & 88,93 & 294,73 & 26,51 \\
\hline Prob $>$ chi $^{2}$ & 0,0000 & 0,0000 & 0,0000 & 0,0000 & 0,0000 & 0,0000 \\
\hline \multirow{2}{*}{$\begin{array}{l}\left.\text { Observações (n. }{ }^{\circ}\right) \\
\left.\text { Municípios (n. }{ }^{\circ}\right)\end{array}$} & 5.556 & 5.432 & 5.576 & 5.516 & 5.564 & 5.576 \\
\hline & \multicolumn{6}{|c|}{29} \\
\hline
\end{tabular}

Nota. Valores dos parâmetros arredondados para quatro casas decimais. *** denota significância estatística a $1 \%$. Fonte: Elaborado pelos autores (2021).

Destaca-se, na Tabela 6, que o número de observações foi reduzido ao analisar as despesas por Grupos de Funções. Como no setor público a contabilização é diferente do setor privado, as contas de função foram aqui agrupadas para se assemelharem aos estudos de cost stickiness que analisam tipos diferentes de contas de custos (típicas da contabilidade do setor privado) e seguindo a lógica de agrupamento do flypaper, que é por similaridade de fonte de receita pública. Tal ocorrência se deu porque alguns municípios não apresentaram despesas inerentes a determinados grupos em alguns períodos. Ao verificar o comportamento das despesas por grupos em relação às receitas totais, observa-se que as estatísticas não foram tão significantes, se comparadas às análises da Tabela 5, possivelmente por conta da imposição do orçamento equilibrado para o setor público.

Para os Grupos 1 (administração e comunicações) e 2 (assistência e previdência social), os coeficientes indicam comportamento assimétrico, ou seja, as despesas aumentaram 0,2509\% e $0,4038 \%$, respectivamente, quando as receitas totais aumentaram $1 \%$. Porém, nesses grupos, as despesas continuaram aumentando $0,0390 \%$ e $0,0793 \%$, quando as receitas reduziram em $1 \%$.

No Grupo 3 (educação e cultura), verifica-se que, para $1 \%$ de crescimento nas receitas totais, as despesas aumentam $0,5356 \%$, mas reduziram apenas $0,0342 \%$ no caso de redução das receitas na mesma proporção. Tais resultados corroboram a proposição presente na literatura, de que gastos desta categoria não podem ser reduzidos tão facilmente, dada a sua função social (Sakurai, 2013). Observa-se que os dados das despesas municipais deste grupo (Figura 1) correspondem a 27,85\% das despesas totais entre 1999 e 2018.

De modo análogo, o Grupo 4 (saúde e saneamento) também demonstrou aumento significativo das despesas $(0,5385 \%)$ diante do aumento de $1 \%$ das receitas, bem como a redução das despesas $(0,1560 \%)$ mediante a diminuição de $1 \%$ das receitas. Este grupo representa $25,14 \%$ da totalidade dos gastos municipais no período analisado. Dessa maneira, os grupos 3 e 4, juntos, compõem mais de $50 \%$ das despesas municipais totais.

O Grupo 5 (habitação, transporte, urbanismo, comércio e serviço) apresentou significativo aumento de $0,8168 \%$ para cada $1 \%$ de aumento nas receitas totais, e diminuiu $0,4032 \%$ quando estas reduziram.

Por fim, quanto ao Grupo 7 (defesa nacional, segurança pública e relações exteriores), nota-se que o coeficiente $\beta_{2}$ foi positivo. Dessa forma, não se pode afirmar que a variação das despesas em função das receitas é assimétrica com base no modelo adotado. Além disso, o valor $\mathrm{p}$ ( $p$-value) para o $\beta_{2}$ ficou acima do nível de significância adotado neste estudo. Assim, não há evidências suficientes para confirmar o comportamento assimétrico nesse grupo.

A Tabela 7 apresenta o resumo dos resultados das três análises realizadas, conforme procedimentos metodológicos descritos, com destaque para o efeito dos custos, segundo a abordagem cost stickiness. 
Tabela 7

\begin{tabular}{c|c|c|c|c}
\hline Comportamento dos custos em municípios catarinenses (1999 a 2018) com base na TCS \\
\hline Receitas & $\begin{array}{c}\text { A cada 1\% de } \\
\text { aumento na } \\
\text { receita, a } \\
\text { despesa } \\
\text { aumenta }\end{array}$ & $\begin{array}{c}\text { A cada 1\% de } \\
\text { redução na } \\
\text { receita, a } \\
\text { despesa diminui }\end{array}$ & Efeito \\
\hline Totais & Totais & $0,4442 \%$ & $0,1468 \%$ & $\begin{array}{c}\text { Assimétrico } \\
\text { (sticky costs) }\end{array}$ \\
\hline Totais & Próprias & $0,0743 \%$ & $0,0220 \%$ & $\begin{array}{c}\text { Assimétrico } \\
\text { (sticky costs) }\end{array}$ \\
\hline Totais & Transferências & $0,4384 \%$ & $0,3043 \%$ & $\begin{array}{c}\text { Assimétrico } \\
\text { (sticky costs) }\end{array}$ \\
\hline Administração e Comunicações & Totais & $0,2191 \%$ & $0,0636 \%$ & $\begin{array}{c}\text { Assimétrico } \\
\text { (sticky costs) }\end{array}$ \\
\hline Assistência e Previdência social & Totais & $0,3930 \%$ & $0,0492 \%$ & $\begin{array}{c}\text { Assimétrico } \\
\text { (sticky costs) }\end{array}$ \\
\hline Educação, Cultura, Desporto e Lazer & Totais & $0,5356 \%$ & $0,0342 \%$ & $\begin{array}{c}\text { Assimétrico } \\
\text { (sticky costs) }\end{array}$ \\
\hline Saúde e Saneamento & Totais & $0,5385 \%$ & $0,1560 \%$ & $\begin{array}{c}\text { Assimétrico } \\
\text { (sticky costs) }\end{array}$ \\
\hline Habitação, Transporte, Urbanismo, & Totais & $0,8168 \%$ & $0,4032 \%$ & $\begin{array}{c}\text { Assimétrico } \\
\text { (sticky costs) }\end{array}$ \\
\hline Comércio e Serviços & Totais & $0,1158 \%$ & $0,1495 \%$ & Inconclusivo \\
\hline Demais Funçoses & \multicolumn{3}{|c}{}
\end{tabular}

Fonte: Elaborado pelos autores (2021).

Portanto constatou-se que o comportamento das despesas em relação às receitas foi assimétrico e sticky em oito dos nove modelos rodados. Todavia os valores dos coeficientes $\mathrm{R}^{2}$ indicam a existência de outros fatores não incluídos no modelo desenvolvido, que podem explicar tal comportamento. Nesse sentido, estudos futuros podem investigar esses fatores e verificar sua influência sobre as despesas públicas em locais e contextos diferentes.

\section{CONSIDERAÇÕES FINAIS}

Nesta pesquisa foram realizadas três análises distintas, por meio de adaptação do modelo estatístico da TCS, de Anderson et al. (2003), para o setor público. A base das adaptações foram os agrupamentos de contas, seguindo-se a lógica do fenômeno flypaper. Dos nove modelos testados, oito confirmaram o fenômeno sticky cost, o que contribui para a TCS que, até então, comumente apresentava testes em amostras do setor privado. Nesse sentido, pode-se responder o problema de pesquisa, na perspectiva dos cost stickiness, com a afirmação de que o comportamento dos custos nos governos locais de Santa Catarina são predominantemente sticky costs. Isso significa que os agrupamentos de custos analisados não diminuem em relação à receita na mesma proporção em que aumentam.

Cabe destacar que, no setor público, há um fenômeno semelhante, chamado de flypaper, que utiliza uma parte reduzida da receita para medir assimetria de custos. Por este motivo e na tentativa de associar o flypaper ao fenômeno cost stickiness, a fim de adaptar a metodologia de cálculo do comportamento de custos da TCS, foram realizados testes em diferentes grupos de contas de receitas e custos. Logo os resultados desta pesquisa devem ser analisados com a ponderação de que foi adaptada a fórmula da TCS, proposta por Anderson et al. (2003).

Os resultados da análise três (por grupos de funções) não foram tão significativos quanto os demais e precisam ser revistos. Portanto, para futuras pesquisas, devem ser analisadas as 
funções de despesas separadamente e, assim, identificar fatores que levam aos cost stickiness em cada área de atuação no setor público. A diversidade de atividades que envolvem os governos e o caráter não lucrativo, transcende as explicações desse fenômeno até agora disponíveis na literatura da TCS.

Assim, os resultados interessam a gestores e pesquisadores que visam o aperfeiçoamento da eficiência nos gastos públicos. Identificar os custos que não se comportam de maneira simétrica pode auxiliar no planejamento e possibilitar a readequação de maneira mais eficiente ao longo do tempo. No setor público, o foco é o equilíbrio, e não o lucro, talvez isso seja um limitador não considerado neste estudo e que requer um olhar diferenciado e aprofundado, já que as finanças públicas têm peculiaridades que precisam ser consideradas.

Como limitações desta pesquisa, destacam-se as adaptações de conceitos, que foram desenvolvidos inicialmente para o âmbito empresarial, a adaptação da fórmula que considerou o agrupamento de contas para maior representatividade dos resultados, a literatura incipiente sobre o comportamento cost stickiness na área pública e a restrição da análise à execução orçamentária dos municípios catarinenses. Outra importante consideração, e que não foi aprofundada nesta pesquisa, é o fato de o setor público não ter como foco o lucro, portanto os resultados tendem a ser equilibrados, como definido na normatização contábil específica dos governos.

O comportamento dos custos no setor público, levando-se em conta a nova abordagem da TCS, é uma lacuna de pesquisa que precisa ser explorada. Contudo, as diferentes nomenclaturas de contas contábeis podem induzir aos erros na adaptação dos modelos privados para o setor público, por isso é importante a padronização de conceitos e termos contábeis. Em resumo, o termo custos é utilizado internacionalmente como sinônimo do total de gastos registrados no período, quando a abordagem é sobre cost stickiness, portanto os custos públicos correspondem às despesas orçamentárias executadas, conforme utilizado neste estudo.

Por fim, vale destacar que, devido às peculiaridades do setor público, o comportamento dos custos pode ser visto sob a ótica de outras teorias, desenvolvidas para o próprio setor, pois não é possível a transposição de técnicas do setor privado sem as devidas adaptações ao setor público.

\section{REFERÊNCIAS}

Anderson, M. C., Banker, R. D., \& Janakiraman, S. N. (2003). Are selling, general, and administrative costs "sticky"? Journal of accounting research, 41(1), 47-63. https://doi.org/10.1111/1475-679X.00095

Barbetta, P.A. (2011). Estatística aplicada às Ciências Sociais. (7a. ed.) Florianópolis: UFSC.

Bracci, E., Humphrey, C., Moll, J., \& Steccolini, I. (2015). Public sector accounting, accountability and austerity: more than balancing the books? Accounting, Auditing \& Accountability Journal, 28(6), 878-908. https://doi.org/10.1108/AAAJ-06-2015-2090

Gamkhar, S., \& Oates, W. (1996). Asymmetries in the response to increases and decreases in intergovernmental grants: some empirical findings. National tax journal, 49(4), 501-512.

Gennari, E., \& Messina, G. (2014). How sticky are local expenditures in Italy? Assessing the relevance of the "flypaper effect" through municipal data. International tax and public finance, 21(2), 324 -344. https://doi.org/10.1007/s10797-013-9269-9

Gujarati, D. (2006). Econometria Básica. (4a. ed.) Rio de Janeiro: Elsevier. 
Helden, J. V., \& Uddin, S. (2016). Public sector management accounting in emerging economies: a literature review. Critical Perspectives on Accounting, 41, 34-62. https://doi.org/10.1016/j.cpa.2016.01.001

Hosomi, S., \& Nagasawa, S. (2018). Empirical study on asymmetric cost behavior: analysis of the sticky costs of local public enterprises. Asia-Pacific Management Accounting Journal (APMAJ), 13(2), 55-82.

Instituto Brasileiro de Geografia e Estatística (IBGE). (2019). Sistema Nacional de índices de Preço ao Consumidor. Índice Nacional de Preços ao Consumidor Amplo - IPCA e Índice Nacional de Preços ao Consumidor - INPC. Recuperado de https://sidra.ibge.gov.br/pesquisa/snipc.

Kandil, M. (2001). Asymmetry in the effects of US government spending shocks: Evidence and implications. The Quarterly Review of Economics and Finance, 41(2), 137-165. https://doi.org/10.1016/S1062-9769(00)00066-1

Lago-Penãs, S. (2008). Local governments asymmetric reactions to grants: causes and $\begin{array}{llll}\text { consequences. Public } & \text { Finance }\end{array}$ https://doi.org/10.1177/1091142107299596

Levaggi, R., \& Zanolla, R. (2003). Flypaper effect and sluggishness: evidence from regional health expenditure in Italy. International Tax and Public Finance, 10, 535-547. https://doi.org/10.1023/A:1026118222901.

Medeiros, O. R., Costa, P. S., \& Silva, C. A. T. (2005). Testes empíricos sobre o comportamento assimétrico dos custos nas empresas brasileiras. Revista Contabilidade e Finanças, 16(38), 47-56. https://doi.org/10.1590/S1519-70772005000200005

Portaria MOG $n^{\circ} 42$, de 14 de abril de 1999 (1999). Atualiza a discriminação da despesa por funções de que tratam o inciso $\mathrm{I}$, do $\S 1^{\circ}$, do artigo $2^{\circ}$, e $\S 2^{\circ}$, do artigo $8^{\circ}$, ambos da Lei $n^{\circ}$ 4.320, de 17 de março de 1964; estabelece os conceitos de função, subfunção, programa, projeto, atividade, operações especiais, e dá outras providências. Brasília, DF. Recuperado de https://www.legisweb.com.br/legislacao/?id=182092

Richartz, F., \& Borgert, A. (2020). Fatores explicativos para o comportamento assimétrico dos custos das empresas listadas na B3. Revista Universo Contábil, 16 (3). https://doi:10.4270/ruc20203XX

Sakurai, S. N. (2013). Efeitos assimétricos das transferências governamentais sobre os gastos públicos locais: evidências em painel para os municípios brasileiros. Pesquisa e Planejamento Econômico, 43(2), 309-332.

Santos, R. S., Ribeiro, E. M., Ribeiro, M. M., \& Pinto, F. L. B. (2017). Administração política e políticas públicas: em busca de uma nova abordagem teórico-metodológica para a (re)interpretação das relações sociais de produção, circulação e distribuição. Cadernos EBAPE.BR, 15(4), 939-959. http://dx.doi.org/10.1590/1679-395155017. 
Suzart, J. A. S. (2012). Sistema federal brasileiro de custos: uma análise comparativa à luz das recomendações da IFAC. Revista de Gestão, Finanças e Contabilidade, 2(3), 39-55.

Suzart, J. A. S., Zuccolotto, R., \& Rocha, D.G. (2018). Federalismo fiscal e as transferências intergovernamentais: um estudo exploratório com os municípios brasileiros. Advances in Scientific and Applied Accounting, 11(1), 127-145. http://dx.doi.org/10.14392/asaa.2018110107

Volden, C. (1999). Asymmetric effects of intergovernmental grants: analysis and implications for U.S. welfare policy. Publius: the journal of federalism, 29(3), 51-73. https://doi.org/10.1093/oxfordjournals.pubjof.a030037

Wu, T. C., Young, C., Yu, C. \& Hsu, H. (2020). Are governmental expenditures also sticky? Evidence from the operating expenditures of public schools. Applied Economics, 52(16), 1763-1776. https://doi.org/10.1080/00036846.2019.1678731 